\title{
Estudo da adsorção do corante azul de metileno em resíduos de babaçu
}

\section{Study of adsorption of methylene blue dye in waste babaçu}

\author{
Paulo Vitor Brandão Leal ${ }^{1 *}$, Airton Messias Gregório ${ }^{1}$, Emiret Otoni ${ }^{1}$, Paulo Roberto da \\ Silva $^{1}$, Maike de Oliveira Krauser ${ }^{1}$ e Juliana Cristina Holzbach ${ }^{1}$ \\ ${ }^{I}$ Departamento de Ciências Exatas e Biotecnológicas; Universidade Federal do Tocantins - Campus Universitário \\ de Gurupi; 77.410-530; Gurupi - TO - Brasil.
}

\begin{abstract}
The prospect of water shortages in the near future illuminates a warning about the indiscriminate use of this feature, since its availability is increasingly limited. This fact makes discussions about the conscious use of water will become increasingly common either by environmental groups, government agencies, researchers, and often in society in general. In this context the search for low cost adsorbent noteworthy, since in many cases, this material must be used in large scale for the treatment of water which prevents the use of a material of high value. The extraction of babassu oil for biofuel production has been extensively studied, but in many cases, the pie from the extraction of oil is disposed of improperly generating environmental impacts. In this context, this paper aims to test the adsorption of the cationic dye methylene blue in babassu to try to add value to a material often irregularly disposed in addition to helping the textile industries in sustainability in relation to water use.
\end{abstract}

Key-words: Hydrolysis, enzymatic solution, alcalase, protease, pectinase

\section{INTRODUÇÃO}

Nas últimas décadas, os problemas ambientais têm se tornado cada vez mais críticos e frequentes, principalmente devido ao desmedido crescimento populacionais e ao aumento da atividade industrial. Com estes ingredientes os problemas devido à ação antrópica têm atingido dimensões catastróficas, podendo ser observadas através de alterações na qualidade do solo, ar e água (Kunz et al., 2002).

A água é um dos recursos mais utilizados pelos seres vivos. É fundamental para a existência e manutenção da vida e, para isso, deve estar presente no ambiente em quantidade e qualidade apropriadas (Braga et al., 2002; Nandi et al., 2008).

A perspectiva de escassez de água em um futuro não muito distante vem chamando a atenção de organizações internacionais, entidades ambientalistas, órgãos de governo e pesquisadores. A previsão de que em 2025 apenas 25\% da humanidade terá água disponível para suas necessidades essenciais vem soando como um alarme e, no Dia Mundial da Água, comemorado em 22 de março, do ano de 2005, a Organização das Nações Unidas (ONU) lançou a Década Internacional de Ação - Água Fonte de Vida. Uma tentativa de ampliar até 2015 o acesso à água, sobretudo nos países do terceiro mundo (Luz, 2008).

Mais de 10 mil tipos de corantes são empregados anualmente pelas indústrias, equivalentes a cerca de 700.000 ton/ano. No Brasil, este número equivalente a $26,5 \mathrm{mil}$ ton/ano. Boa parte deste material é descartada nos corpos hídricos, representando um problema ambiental e perda na renda da indústria (Monteiro, 2010).

Os corantes são visualmente detectáveis e causam sérios problemas de natureza estética nos corpos d'água receptores, mesmo quando presentes em pequenas quantidades. Além disso, a maioria dos corantes é resistente à biodegradação, à fotodegradação e à ação de agentes oxidantes e alguns são suspeitos de induzirem efeitos

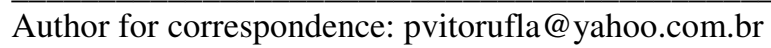


carcinogênicos e/ou mutagênicos (Neumann, 2000).

O azul de metileno é um corante catiônico bastante empregado. Essa molécula é bastante estudada uma vez que ela se apresenta como modelo já que as bandas de absorção de suas diferentes espécies (monômeros, dímeros, agregados e espécies protonadas) são bem conhecidas e aparecem em regiões distintas do espectro (Neumann, 2000; Brady, 1996).

Várias tecnologias são aplicadas para remoção de poluentes da água que incluem precipitação química, osmose, evaporação, flotação de íons, troca iônica e adsorção (Babu e Gupta, 2008).

A melhor escolha de um método universal adequado para eliminar todos os poluentes dos efluentes depende do tipo de substância a ser removida, composição, concentração e fluxo de produção do efluente (Belisário et al., 2009).

Dentre os métodos de tratamento, a adsorção tem se destacado como uma técnica de separação principalmente por ser um processo de alta seletividade, a nível molecular, demonstrando-se eficaz e econômica (Belisário et al., 2009).

Devido à preocupação com relação à preservação do meio ambiente, vem crescendo a procura por materiais de baixo custo para serem utilizados como adsorventes de corantes em meio aquoso. Esta procura tem se tornado cada vez mais evidente já que diferentes indústrias (têxtil, papel, plástico, couro, dentre outras) geram uma grande quantidade de efluentes contendo resíduos de corantes que, se não forem tratados adequadamente, podem causar um grande problema de contaminação ambiental (Kunz et al., 2002; Pereira et al., 2008; Vijayaraghavan et al., 2008).

A adsorção é um processo espontâneo que ocorre sempre que uma superfície de um sólido (adsorvente) é exposta a um gás ou a um líquido (adsorvato). Mais precisamente pode definir-se adsorção como o enriquecimento de um dado fluido, ou o aumento da densidade desse fluido na vizinhança da interface (Atkins, 2008).

O babaçu é uma palmeira muito comum nos estados do Maranhão, Piauí, Pará e Tocantins e por se tratar de uma planta oleaginosa seu estudo para a produção de biocombustível vem sendo difundido. Porém a extração do óleo vegetal gera um resíduo sólido conhecido como torta que muitas vezes é descartado de forma inadequada.

Diante do exposto, o presente trabalho visa testar a adsorção de soluções de azul de metileno em resíduos de babaçu para uma possível aplicação no tratamento de efluentes.

\section{MATERIAL E MÉTODOS Adsorvato}

A partir de uma solução estoque de azul de metileno $\left(1 \mathrm{~g} \mathrm{~L}^{-1}\right)$ foram realizadas diluições para construção da curva analítica $(10 ; 30 ; 50 ; 70 ; 100$; 250 e $500 \mathrm{mg} \mathrm{L}^{-1}$ ) e para as cinéticas de adsorção.

\section{Adsorvente}

$\mathrm{O}$ babaçu in natura foi obtido da região de Gurupi -TO. Após a colheita, foram conduzidos para o Laboratório de Química da Universidade Federal do Tocantins, Campus Universitário de GurupiTO. Em seguida, o mesocarpo foi ralado para obter o pó, condição favorável para utilização.

\section{Experimentos de adsorção}

Os experimentos de adsorção foram realizados em batelada, utilizando-se uma mesa agitadora (shaker) com velocidade de agitação de $100 \mathrm{rpm}$, temperatura de $25^{\circ} \mathrm{C}, 10 \mathrm{~mL}$ de solução de adsorvato e babaçu. No estudo da cinética foi encontrado o tempo de equilíbrio entre adsorvente e adsorvato (definidos pela cinética de 24 horas). Os testes subsequentes foram realizados considerando esse tempo de equilíbrio. Para a análise da influência da concentração foram preparadas soluções de concentração: 100, $250 \mathrm{e}$ $500 \mathrm{mgL}^{-1}$ à partir da solução estoque. Os testes realizados para diferentes relações entre adsorvente adsorvato consideraram as razões: $1 / 50,1 / 100$ e $1 / 200$ sendo que essas equivalem a relação entre massa de adsorvente (em gramas) por volume de adsorvato (em $\mathrm{mL}$ ). A influência do $\mathrm{pH}$ na adsorção foi avaliada. Para tal foram preparadas soluções com $\mathrm{pH}=4$ (ácido), $\mathrm{pH}=7$ (neutro) e $\mathrm{pH}=10$ (básico). Os valores de $\mathrm{pH}$ foram ajustados utilizando-se ácido acético concentrado $(\mathrm{pH}=4)$ e solução de $\mathrm{KOH} 0,1 \mathrm{molL}^{-1}(\mathrm{pH}=10)$.

Após o contato entre adsorvente e adsorvato as soluções foram centrifugadas, e realizou-se leituras do sobrenadante em espectrofotômetro de UV-visível em um comprimento de onda de 645 nm.

\section{RESULTADOS E DISCUSSÃO Tempo de contato}

O estudo da influência do tempo de contato na remoção de azul de metileno foi realizado em um sistema de batelada, com concentração inicial de 
solução de azul de metileno $100 \mathrm{mgL}^{-1}$, relação de massa de adsorvente por volume de solução de 1:100, $\mathrm{pH}=7$, utilizando como adsorvente babaçu in natura. Foram tomadas amostras em um período de tempo variando de 0,17 a 24 horas. Os resultados estão dispostos na figura 1 .
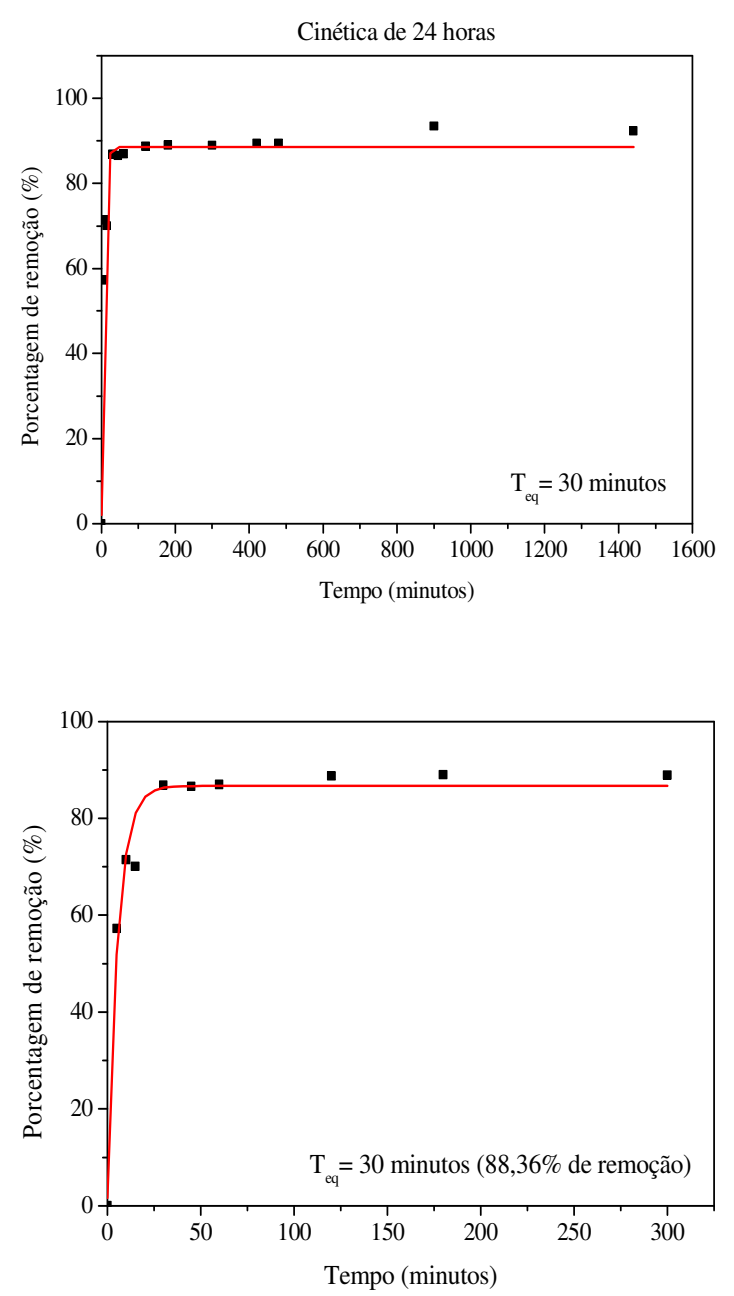

Figura 1- Cinética de adsorção de solução de azul de metileno em babaçu (a) até 24 horas (b) até cinco horas.

Observa-se que o equilíbrio de adsorção foi atingido após 30 minutos com remoção de cerca de $88 \%$ da concentração inicial. Assim, para garantir a realização dos experimentos em condições de equilíbrio, as análises subsequentes, foram realizadas utilizando cinco horas como garantia para o equilíbrio.

\section{Influência da concentração}

Os resultados da influência da concentração inicial na adsorção do corante azul de metileno em resíduos de babaçu estão apresentados na figura 2 .

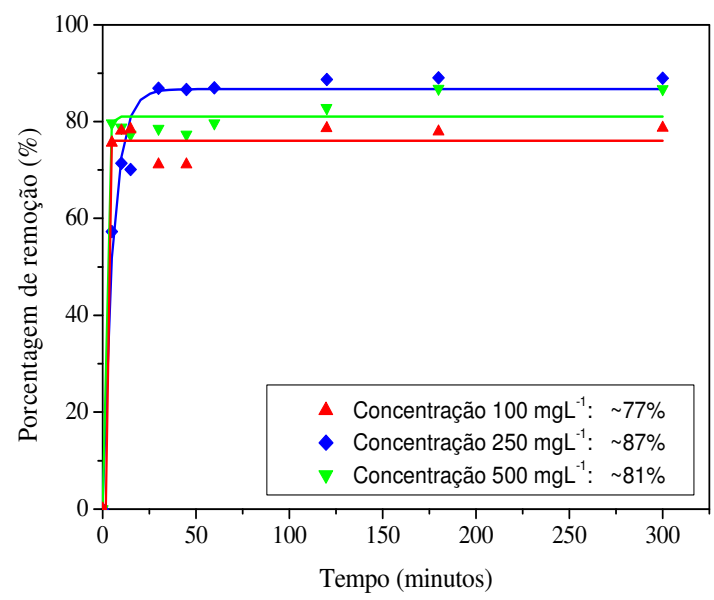

Figura 2- Comparativo da adsorção de solução de azul de metileno em diferentes concentrações.

O aumento da concentração de $100 \mathrm{mgL}^{-1}$ para 250 $\mathrm{mgL}^{-1}$ aumentou a eficiência de adsorção. Isso pode ser explicado pelo fato de que a baixas concentrações, existiria ainda uma grande quantidade de locais disponíveis para que ocorresse a adsorção. Ao aumentar a concentração inicial de azul de metileno, haveria mais espécies distribuídas na superfície do adsorvente, o que contribui para uma maior formação de ligações químicas na superfície.

A diminuição da eficiência de adsorção quando a concentração foi de $500 \mathrm{mgL}^{-1}$ se deve ao fato de que após a saturação não ocorre mais o processo de adsorção e o excesso de soluto pode ter gerado competição (Carvalho et. al.,2010; Magriotis et. al., 2010; Peres et al., 2011). Assim a concentração ótima de solução de azul de metileno foi $250 \mathrm{mgL}^{-}$ 1.

\section{Relação massa de adsorvente por volume da solução de azul de metileno}

Os resultados da razão entre massa de adsorvente (em gramas) por volume de solução de azul de metileno (em mL) estão apresentados na figura 3. 


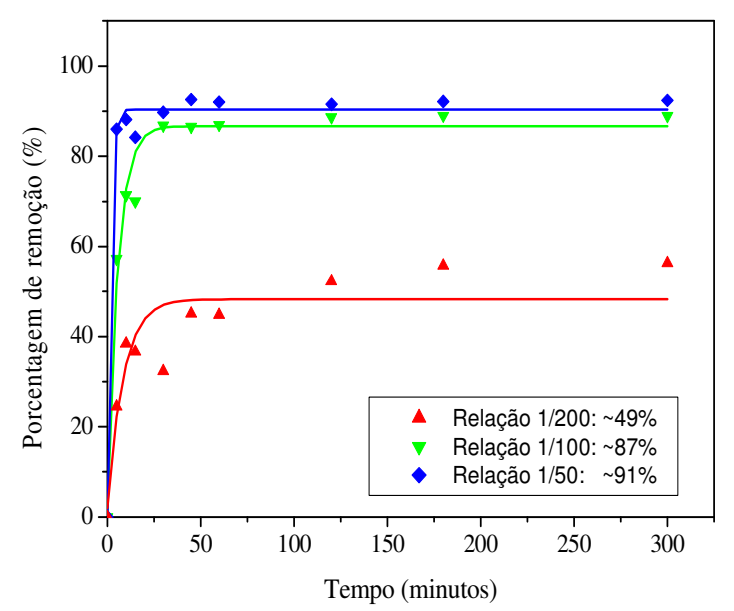

Figura 3- Influência da quantidade de adsorvente na adsorção de solução de azul de metileno.

A eficiência de adsorção aumentou quando a quantidade de adsorvente aumentou de $0,05 \mathrm{~g}$ (1:200) para 0,1g (1:100). Essa maior eficiência pode ser explicada pelo aumento da área superficial onde ocorre a adsorção. Entretanto o aumento da quantidade de adsorvente para $0,2 \mathrm{~g}$ (1:50) não acarretou mudanças significativas na adsorção. A proximidade da adsorção das relações 1:100 e 1:50 pode ser explicada pelo fato que as forças de adsorção podem estar diminuindo, já que se tem uma maior extensão da superfície para uma mesma quantidade de adsorvente, quando se tratar de uma adsorção química. Desse modo considerou-se a relação 1:100 para as análises subsequentes.

\section{Influência do pH}

A influência do pH na adsorção de solução de azul de metileno foi investigada em $\mathrm{pH}=4,7$ e 10 . Os resultados estão apresentados na figura 4 .

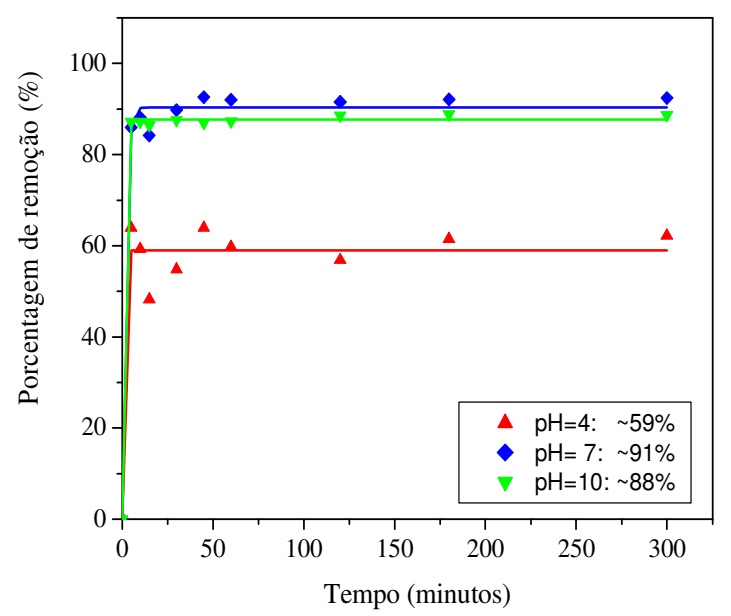

Figura 4- Influência do pH na adsorção da solução de azul de metileno.

A partir da figura 4 é possível observar uma proximidade entre os valores de $\mathrm{pH}=7$ e $\mathrm{pH}=10$. Porém o valor obtido para $\mathrm{pH}=4$ foi bem inferior. Esse resultado pode ser explicado pelo fato do azul de metileno ser uma molécula de caráter catiônico, desse modo em $\mathrm{pH}=4$ poderá ocorrer uma competição entre os íons $\mathrm{H}^{+}$em solução e essas moléculas diminuindo a eficiência de adsorção nesse pH (Petroni e Pires, 2000; Souza et. al., 2007; Bueno e Carvalho, 2007).

Desse modo o $\mathrm{pH}=7$ foi considerado como ótimo por esse ser o próprio $\mathrm{pH}$ da solução.

\section{CONCLUSÃO}

A partir dos resultados obtidos foi possível observar um tempo de equilíbrio relativamente baixo (cerca de 30 minutos) sendo essa característica importante na busca por adsorventes alternativos.

As condições ideais de adsorção foram: concentração inicial de $250 \mathrm{mgL}^{-1}$, relação massa de adsorvente por volume de adsorvato de 1:100 e $\mathrm{pH}=7$.

Foi possível observar uma diferença significativa em $\mathrm{pH}=4$, tal fato pode ser explicado pela ocorrência de competição entre as moléculas de azul de metileno e os íons $\mathrm{H}^{+}$pelos sítios ativos da superfície do babaçu.

Os resultados obtidos na adsorção de solução de azul de metileno em resíduos de babaçu mostram o potencial promissor do uso desse material como adsorvente, uma vez que foi possível obter uma alta porcentagem de remoção (cerca de $88 \%$ nas 
condições ideais) além de se tratar do material in natura.

\section{RESUMO}

A perspectiva de escassez de água em um futuro próximo acende um sinal de alerta sobre o uso indiscriminado desse recurso, uma vez que sua disponibilidade está cada vez mais limitada. Esse fato faz com que discussões sobre o uso consciente da água se tornem cada vez mais comuns seja por entidades ambientalistas, órgãos governamentais, pesquisadores e muitas vezes, na sociedade de um modo geral. Nesse contexto a busca por adsorvente de baixo custo merece destaque, já que, em muitos processos, esse material deve ser utilizado em larga escala para o tratamento da água, fato que inviabiliza o uso de um material de alto valor. A extração de óleo do babaçu para produção em biocombustível vem sendo bastante estudada, porém, em muitos casos, a torta proveniente da extração do óleo é descartada de forma inadequada gerando impactos ambientais. Nesse contexto o presente trabalho visa testar a adsorção do corante catiônico azul de metileno em babaçu para tentar agregar valor a um material muitas vezes descartado de forma irregular além de auxiliar as indústrias têxteis na sustentabilidade em relação ao uso da água.

Palavras-chave: Adsorção, babaçu, corante catiônico

\section{REFERÊNCIAS}

Atkins, P. W. (2008), Físico-Química. 2, 8. Ed. $427 \mathrm{p}$.

Babu, B. V. e Gupta, S. (2008), Adsorption of Cr (VI) using activated neen leaves: kinetics studies. Adsorption. 14, 85-92.

Belisário, M.; Borges, P. S.; Galazzi, R. M.; Piero, P. B. Del; Zorzal, P. B.; Ribeiro, A. V. F. N.; Ribeiro, J. N. (2009), O emprego de resíduos naturais no tratamento de efluentes contaminados com fármacos poluentes. Inter Science Place. 10.

Brady, V. P.; Cygan, T. R.; Nagy, L. K. (1996), Molecular controls on kaolinite surface change. Journal of Colloid Interface Science. 183, 356364.

Braga, B.; Hespanhol, I..; Conejo, J. G. L.; Barros, M. T.; Spencer, M.; Porto, M.; Nucci, N.; Juliano, N.; Eiger, S. (2002), Introdução à Engenharia Ambiental. São Paulo: Prentice Hall, 305p.

Bueno, C. I. C. e Carvalho, W. A. (2007), Remoção de chumbo (II) em sistemas descontínuos por carvões ativados com ácido fosfórico e com vapor. Química Nova, 30, 19111918.

Carvalho, T. E. M.; Fungaro, D. A.; Izidoro, J. C. (2010), Adsorção do corante reativo laranja 16 de soluções aquosas por zeólitas sintéticas. Química Nova. 33, 358-363.

Kunz, A.; Peralta-Zamora, P.; Moraes, S. G.; Durán, N. (2002), Novas Tendências nos tratamentos de Efluentes Têxteis. Química Nova. 25, 78-82.

Luz, B. A. (2005), A importância da água na mineração. Informativo do Centro de Tecnologia Mineral. Ano VI, no 1, jan/mar5.

Magriotis, Z. M.; Leal, P. V. B.; Sales, P. F.; Papini, R. M.; Viana, P. R. M. (2010), Adsorption of etheramine on kaolinite: a cheap alternative for the treatment of mining effluents. Journal of Hazardous Materials. 184, 465-471.

Monteiro, S. M. Mesocarpo de coco verde (cocos nucífera) e pó de serragem da Tatajuba (Bagassa Guianensis Aubi) como adsorventes em meio aquoso. Dissertação (Mestrado em Química), Universidade Federal do Maranhão, 2010.

Nandi, B. K.; Goswami, A.; Purkait, M. K. (2008), Removal of cationic dyes from aqueous solutions by kaolin: Kinetic and equilibrium studies. Applied Clay Science, 42, 583-591.

Neumann, M. G; Gessner, F; Cione A. P. P; Sartori A. R; Cavalheiro, S. C. C. (2000), Interações entre corantes e argilas em suspensão aquosa. Química Nova. 23, 818-824.

Pereira, E.; Oliveira, L. C. A.; Vallone, A.; Sapag, K. (2008), Preparação de carvão ativado em baixas temperaturas de carbonização a partir de rejeitos de café: utilização de $\mathrm{FeCl}_{3}$ como agente ativante. Química Nova. 31, 1296-1300.

Perez, A. A.; Sánchez, C. C.; Patino, J. M. R.; Rubiolo, A. C.; Santiago, L. G. (2011), Surface adsorption behaviour of milk whey protein and pectin mixtures under conditions of air-water interface saturation. Colloids and Surfaces B: Biointerfaces. 85, 306-315. 
Petroni, S. L. G. e Pires, M. A. F. (2000), Adsorção de zinco e cádmio em colunas de turfa. Química Nova, 23, 477-481.

Souza, K. S.; Filha, V. L. S. A.; Pinto, V. H. A.; Fonseca, M. G.; Espínola, J. G. P.; Arakaki, L. N. H. (2007), Quimissorção de cátions divalentes em sílica gel modificada com ácido tioglicólico - a influência do ph e força iônica. Química Nova, 30, 528-534.
Vijayaraghavan, K.; Won, S. W.; Mao, J.; Yun, Y. (2008), Chemical modification of Corynebacterium glutamicum to improve methylene blue biosorption. Journal of Chemical Engineering. 45, 1-6. 